\title{
Psychometric Properties of the Persian Version of the Sibling Cancer Needs Instrument (SCNI)
}

\author{
Zeynab Masoudifar ${ }^{1}$, Leila Khanali Mojen ${ }^{1 *}$, Maryam Rassouli ${ }^{1}$, Maliheh Nasiri ${ }^{1}$, \\ Pandora Patterson ${ }^{2}$, Fiona Mc Donald ${ }^{2}$, Peyman Eshghi ${ }^{3}$
}

\begin{abstract}
The sibling cancer needs instrument (SCNI) is the first developed specifically for assessing psychosocial unmet needs of adolescents having a sibling with cancer. The aim of this study is to evaluate the psychometric properties of its Persian version. Methods: For this methodological study, the SCNI was translated into Persian using back-translation and revised according to the comments of the developer of the instrument. Then face validity, content validity, construct validity, internal consistency and the stability of the Persian version of the instrument were measure, by examining a population of 180 adolescents having a sibling with cancer in six hospitals in Tehran, Iran. The data were analyzed using SPSS version 16 and EQS version 6.1. Results: Confirmatory factor analysis approved the construct validity of the instrument and its seven domains. Cronbach's alpha was measured as 0.97 for the total instrument and 0.80- 0.92 for its seven domains. In order to evaluate ttest-retest reliability, the intra-class correlation coefficient (ICC) was also calculated (0.94). Conclusions: The Persian version of SCNI has acceptable psychometric properties. It can be used for measuring the unmet psychosocial needs in adolescents who have a sibling with cancer in the Persian-speaking population.
\end{abstract}

Keywords: Psychometrics- cancer- adolescent- sibling- needs assessment

Asian Pac J Cancer Prev, 19 (12), 3457-3462

\section{Introduction}

Adolescence is one of the most sensitive periods in which one faces rapid physical, emotional, cognitive and social changes, and is one of the significant stages in human development, a critical and risky period of life. Adolescence is a transitional period between childhood and adulthood, which begins with puberty and is one of the most critical periods of life and an important stage in psychosocial development. Facing any tensions in this period can result in health problems such as depression, anxiety, and behavioral disorders (Rachele et al., 2013; Clinton-McHarg et al., 2010; Azarbarzin et al., 2015).

One of the tense incidents is the diagnosis of cancer in one of the family's children. It may cause complications in the adjustment of an adolescent family member such as a sibling of the child with cancer, and has consequences such as less communication with parents, changes in the sibling's relations, feeling jealous of the sick child and being angry with parents (Prchal and Landolt, 2012; Peek and Melnyk, 2010; Grant et al., 2012; Dambi et al., 2015). In such a situation, the adolescent may feel isolated and neglected due to his/her inability to adapt to the situation, being more vulnerable during puberty regarding parents' focus on the needs of the sick family member. Moreover, he/she displays negative behavioral and emotional responses, due to his/her unmet psycho-social needs (McDonald et al., 2015; Patterson et al., 2014; Yang et al., 2016; Silbermann et al., 2015). Since most parents often ignore the psychosocial needs of adolescents, paying attention to their needs would be necessary (Sooki et al., 1389).

A study on the siblings of the children with thalassemia in Iran showed that in addition to the children with thalassemia, their siblings have more psychosocial problems than other healthy children, too. It is necessary to consider the siblings of the children with thalassemia in care programs (Arab et al., 2012). The results of the conducted studies show that if one child is chronically ill in a family, other adolescent members have difficulties adapting to the changes. They, consequently, display various behavioral and psychological responses. However, their needs are least recognized and met, compared with other family members (Patterson et al., 2011; Alderfer and Hodges, 2010). Therefore, it's important to recognize the needs of adolescents with a sibling with cancer, in order to design and implement health promotion programs for them. So, in order to identify these adolescents' needs,

${ }^{1}$ School of Nursing and Midwifery, ${ }^{3}$ Pediatric Congenital Hematologic Disorders Research Center, Research Institute for Children's Health, Shahid Beheshti University of Medical Sciences, Tehran, Iran, ${ }^{2}$ Can Teen, The Australian Organisation for Young People Living with Cancer, Sydney, Australia. *For Correspondence: leilakhanali@yahoo.com 
comprehensive instruments are necessary for initial screening or monitoring of their needs while their sibling has cancer (Sahib-Alzamani et al., 1389; Patterson et al., 2011).

The Sibling Cancer Needs Instrument (SCNI) is the only professional instrument in this field which has been designed and psychometrically evaluated by Patterson et al., (2011). It has 45 items in 7 domains, and a proper validity regarding to its acceptable reliability and the confirmed construct validity in comparison to Kessler10 instrument.

So far, no study in Iran has been conducted on the psychosocial needs of adolescents who have a sibling diagnosed with cancer. It seems that one reason is the lack of a valid and reliable instrument in Iran able to assess these needs. In order to ensure meeting this group of adolescents' needs, it's important to measure them. Therefore, the aim of this study was the psychometric evaluation of the Persian version of "Sibling Cancer Needs Instrument".

\section{Materials and Methods}

The present research is a methodological research in which the psychometric properties of the Persian version of the Sibling Cancer Needs Instrument (SCNI) were evaluated.

\section{Sibling Cancer Needs Instrument (SCNI)}

This instrument was first developed by Paterson et al, in 2011, to determine the psychosocial needs of the adolescents and youth who have a sibling with cancer. Initially, it included 80 items in 10 domains, which were reduced to 73 items after doing an exploratory factor analysis (Patterson et al., 2011).

Then, in 2014, psychometric properties of the instrument were evaluated by studying 106 adolescent and young participants aged 12-24 who had a brother or sister with cancer. In assessing the validity of the instrument, content validity, face validity and construct validity were measured. After performing Factor Analysis, 45 items were categorized in the following 7 domains: Information about my sibling's cancer, "Time out" and recreation, Practical assistance, Support from my friends and other young people, Dealing with feelings, Understanding from my family, My relation with my sibling with cancer.

Reliability was also confirmed by measuring internal consistency ( $\alpha=0.90-0.95)$ and test-retest reliability $(\mathrm{r}=0.88)$. This instrument assesses needs by a 4-point scale $(1=$ no need, $2=$ low need, $3=$ moderate need, $4=$ strong need). Higher scores are the indicator of the adolescent's higher amount of need (Patterson et al., 2014).

Method: At first, after gaining the instrument designer's permission, the Sibling Cancer Needs Instrument (SCNI) was translated to Persian by two expert English translators, based on the WHO's guidelines for the Process of Translation and Cultural Adaptation of Instruments. Then the Persian version was again translated into English regardless of the original instrument. Finally, after comparing two English versions (the original version and the other one, translated into English regarding the Persian translation) the necessary amendments were made and then a copy of the final English translation was sent to the instrument designer for approval. Then, according to her comments and the amendments applied by the research team, the final Persian form of the revised version of the instrument was developed.

In order to evaluate the psychometric properties of the Sibling Cancer Needs Instrument (SCNI), face validity, content validity and construct validity were measured as well as the internal consistency (Cronbach's alpha) and the test-retest reliability.

To determine qualitative content validity and face validity, the translated version and the original version of the instrument were given to 10 experts and faculty members (experts in nursery, cancer and psychometrics) to be reviewed. These experts also checked and confirmed the face validity of the translated instrument. Then, the instrument was offered to 10 adolescents in the research population. They were asked to express their ideas on its usability and also the understandability of the sentences and items.

In the next step, in order to measure the construct validity of the instrument, adolescents aged from 12 to 19 were chosen, all of whom had a brother or sister with cancer referring to the selected medical centers affiliated with the University of Tehran. It should be noted that Tehran hospitals are the referral centers for all cancer patients from all over Iran. They can be considered as the representative of the Iranian adolescents who have a brother or sister with cancer.

A purposive sampling was used to reach the appropriate sample size to measure construct validity. A total of 180 samples were examined for this study. The adolescent participants of the study aged between 12 and 19, who had a brother or sister diagnosed with cancer (in any stage and type) at least six months before the research and also alive at the time the research was conducted.

The adolescents were aware of their sibling's disease, able to speak Persian and literate (writing and reading ability). They had not encountered any other tense events in the last six months, and didn't have any specific chronic diseases either, as they themselves said.

At this stage, after obtaining the permit for doing the research, and making the necessary research coordination, the adolescents were selected based on entry criteria. After obtaining a consent letter from them and their parents for participating in the study, the adolescents were asked to complete "Sibling Cancer Needs Instrument", as well as a demographic questionnaire (consists of 15 items on age, educational and occupational data of the adolescents, their parents and the siblings with cancer (Refer to in Table 1). The process was as follows: after selecting the intended patient, his/her adolescent brother or sister was contacted by the patient, the family or the researcher, and a certain time was agreed upon for completing the instrument. If the adolescent could come to the hospital, he/she filled the instrument there; otherwise, it was handed to the family along with the complete instructions, and was received later upon completion.

The construct validity of the instrument was evaluated, 
considering the Confirmatory Factor Analysis and the Fit Indices, such as the Chi-square test to the degree of freedom ratio, NNFI, CFI, GFI, RMSEA and NFI. In the current study, descriptive statistics were used to describe the demographic data and SPSS version 16 and EQS version 6.1 soft wares were used for data analysis.

In order to evaluate the reliability, the internal consistency (Cronbach's $\alpha$ ) and test-retest reliability were measured. In order to assess the consistency, the instrument was given to 15 participants in the research on two occasions with a two- week interval. Then the intra-class correlation was calculated.

In order to observe ethical considerations, the research objectives were explained to all participants. The privacy and confidentiality of information and data anonymization were ensured in all stages of the research. The present study was registered with number IR.SBMIU. PHNM.1395.472 in the research council of the School of Nursing and Midwifery of Shahid Beheshti University of Medical Sciences. The required permits for sampling were obtained and submitted to the corresponding organs.

\section{Results}

In total, the data gathered from 180 adolescents were analyzed. The mean age of the examined subjects was $15.66 \pm 2.55$, and most of them were girls (98 cases). The demographic data of the research participants is presented in Table 1.

In the process of translating the instrument, there were ambiguities in items 11, 26, 27 and 28 of the original version (Dealing with...) and the translated version (getting along with...). The issue was shared with the designer and he confirmed the translated phrase. There were also ambiguities in item 34 of the original version (For my family to acknowledge that this is happening to me too) and the translated one (My family acknowledge that this may happen to me too) as well as the 45 item of original version (To feel included in my sibling's cancer experience) and the translated phrase (I feel that I have

Table 1. Demographics of Adolescent with a Sibling with Cancer

\begin{tabular}{|c|c|c|c|c|c|c|c|}
\hline variable & groups & amount & percentage & variable & groups & amount & percentage \\
\hline \multirow[t]{5}{*}{ Adolescent age (year) } & $12-14$ & 70 & 38.89 & \multirow[t]{5}{*}{ Father's education } & Illiterate & 22 & 12.2 \\
\hline & $15-17$ & 50 & 27.77 & & Primary & 41 & 22.8 \\
\hline & \multirow[t]{3}{*}{$18-19$} & \multirow[t]{3}{*}{60} & \multirow[t]{3}{*}{33.34} & & Secondary & 34 & 18.9 \\
\hline & & & & & High school & 47 & 26.1 \\
\hline & & & & & University & 36 & 20.0 \\
\hline \multirow[t]{4}{*}{ Adolescent gender } & Girl & 98 & 54.4 & \multirow[t]{4}{*}{ Mother's age (year) } & $\leq 30$ & 5 & 2.78 \\
\hline & \multirow[t]{3}{*}{ Boy } & \multirow[t]{3}{*}{82} & \multirow[t]{3}{*}{45.6} & & $40-31$ & 113 & 62.78 \\
\hline & & & & & $50-41$ & 51 & 28.33 \\
\hline & & & & & $\geq 51$ & 11 & 6.11 \\
\hline \multirow[t]{4}{*}{ Adolescent's education } & Primary & 38 & 21.1 & \multirow[t]{4}{*}{ mother occupation status } & Employee & 9 & 5.0 \\
\hline & Secondary & 52 & 28.9 & & House hold & 166 & 92.2 \\
\hline & High school & 55 & 30.6 & & Retired & 1 & 0.6 \\
\hline & University & 35 & 19.4 & & Other & 4 & 2.2 \\
\hline \multirow[t]{5}{*}{ Adolescent occupation status } & Student & 150 & 83.3 & \multirow[t]{5}{*}{ mother's education } & Illiterate & 24 & 13.3 \\
\hline & Free job & 10 & 5.6 & & Primary & 37 & 20.5 \\
\hline & Worker & 4 & 2.2 & & Secondary & 41 & 22.8 \\
\hline & \multirow[t]{2}{*}{ other } & \multirow[t]{2}{*}{16} & \multirow[t]{2}{*}{8.9} & & High school & 50 & 27.8 \\
\hline & & & & & University & 28 & 15.6 \\
\hline \multirow{3}{*}{$\begin{array}{l}\text { Number of children in the } \\
\text { family }\end{array}$} & $\geq 3$ & 129 & 71.7 & \multirow[t]{3}{*}{ Patient's age (year) } & $1-10$ & 113 & 62.78 \\
\hline & $4-5$ & 33 & 18.3 & & $11-20$ & 55 & 30.55 \\
\hline & $\geq 5$ & 18 & 10 & & $30-21$ & 12 & 6.67 \\
\hline \multirow{3}{*}{$\begin{array}{l}\text { Adolescent sequence in the } \\
\text { family }\end{array}$} & First & 101 & 56.1 & \multirow[t]{3}{*}{ Patient gender } & Girl & 81 & 45.00 \\
\hline & Middle & 57 & 31.7 & & Boy & 99 & 55.00 \\
\hline & Last & 22 & 12.2 & & & & \\
\hline \multirow[t]{4}{*}{ Father age (year) } & $\leq 40$ & 55 & 30.56 & \multirow[t]{4}{*}{ Time from diagnosis(year) } & 1 & 100 & 55.55 \\
\hline & $50-41$ & 94 & 52.22 & & 2 & 47 & 26.12 \\
\hline & $60-51$ & 22 & 12.22 & & 3 & 15 & 8.33 \\
\hline & $\geq 61$ & 9 & 5 & & $3 \leq$ & 18 & 10.00 \\
\hline \multirow[t]{5}{*}{ Father occupation status } & Employee & 32 & 17.8 & & & & \\
\hline & Free work & 78 & 43.4 & & & & \\
\hline & Worker & 53 & $29-.4$ & & & & \\
\hline & Retired & 8 & 4.4 & & & & \\
\hline & Other & 9 & 5 & & & & \\
\hline
\end{tabular}


Table 2. The Indices of Fitness of the Model of CFA for Persian Version of SCNI

\begin{tabular}{lcc}
\hline Fit index type & $\begin{array}{c}\text { Observed } \\
\text { value }\end{array}$ & $\begin{array}{c}\text { Acceptable } \\
\text { value }\end{array}$ \\
\hline Chi-square/df & 1.87 & $<3$ \\
$\begin{array}{l}\text { Root Mean Square Error of } \\
\text { Approximation (RMSEA) }\end{array}$ & 0.07 & $<0 / 08$ \\
Normed Fit Index (NFI) & 0.95 & $>0 / 09$ \\
Non-Normed Fit Index (NNFI) & 0.97 & $>0 / 09$ \\
Comparative Fit Index (CFI) & 0.97 & $>0 / 09$ \\
Goodness of Fit Index (GFI) & 0.8 & $>0.09$ \\
\hline
\end{tabular}

contributed to my sister's/ brother's cancer experience) which were corrected based on his comments. Considering the face validity of the questionnaire, all phrases were confirmed, except for some minor changes in several words.

In this study, a Confirmatory Factor Analysis was performed to assess the construct validity of the instrument. The Chi-square to degree of freedom ratio was measured 1.87 for the 7 factor model. Other goodness of fit indices such as NNFI, NFI, RMSEA, GFI and CFI were also measured (Table 2).

Cronbach's alpha (internal consistency) was measured 0.97 for the whole instrument and 0.80 to 0.92 for the instrument domains. In measuring the reliability, an Intra-class Correlation Coefficient (ICC) of 0.94 was obtained. The results of the Confirmatory Factor Analysis are shown in Table 3.

\section{Discussion}

Being diagnosed with cancer is a stressful incident that affects not only the patient but also family members. Since assessing family needs is of great importance in such a situation, the existence of a valid and reliable instrument can be of help in this regard. Therefore, the present study was carried out to evaluate the psychometric properties of the SCNI in Iran. The results show that the Persian version of Sibling Cancer Need Instrument is consistent with the original version. It consists of 7 domains and 45 items, applicable for any Iranian adolescents who have a sibling diagnosed with cancer.

One of the criteria for evaluating the instrument is its validity. Validity has different aspects, one of which is construct validity. Construct validity of an instrument depends on what exactly it aims to measure (Patterson et al., 2014).

The construct validity of the current study was measured using Confirmatory Factor Analysis. The results confirmed the instrument having 7 domains which is consistent with the original version of the instrument (Patterson et al., 2014).

The domain of Information about my sibling's cancer expresses the necessity for adolescents to access information on their sibling's cancer, as well as treatment, side effects, rehabilitation and prognosis (Patterson et al., 2011). This was in line with the results of Decker et al., (2004) which reported that adolescents are in high need of receiving information on the disease, its treatment and its side effects (Zebrack et al., 2014). Nolbris and Hellström (2005) also showed that the siblings of the people who died from cancer, were not satisfied with the amount of information provided for them by parents and caregivers at the time of their sibling's cancer incidence, and stated that this lack of information had been stressful to them and that they would prefer to know more about the disease, its side effects and care-giving process. When a family member develops a disease, the adolescent expects to be aware of the sibling's treatment procedure and to participate in the care-giving process. Therefore, the need to receive information based on justifying facts is considered as one of their needs (Hockenberry and Wilson 2015).

The domain of Time out and recreation is another domain of adolescents' needs in order to relieve the pressure of having a sibling with cancer (Patterson et al., 2011). It is consistent with the domain of Time out and recreation in Needs Inventory for Siblings of Critically Ill Children (IBesFEMS) instrument. This instrument with proper face, content and construct validities and also appropriate reliability, is a suitable instrument for assessing the needs of this group of siblings. Its similar domains with the current research instrument indicate its proper factor structure (Olivier d'avignon et al., 2017).

The study of Arab et al., (2012) on the siblings of the children with thalassemia in Iran, which is also in line with this domain of the current instrument, showed that despite all the challenges, the need to spend some time for them, have leisure time and also some good time with family is one the siblings main priorities. Furthermore, in

Table 3. Cronbach's Alpha and ICC Amounts for Persian Version of SCNI and Its Subscales

\begin{tabular}{lccccc}
\hline Domains & $\begin{array}{c}\text { Number } \\
\text { of items }\end{array}$ & $\begin{array}{c}\text { Cronbach's } \\
\text { alpha }\end{array}$ & $\begin{array}{c}\text { ICC } \\
\text { (single measures) }\end{array}$ & $\begin{array}{c}\text { ICC } \\
\text { (average measures) }\end{array}$ & $\begin{array}{c}\text { P- } \\
\text { value }\end{array}$ \\
\hline Information about my siblings cancer & 8 & 0.89 & 0.86 & 0.92 & $<0.001$ \\
Time out and recreation & 6 & 0.88 & 0.83 & 0.91 & $<0.001$ \\
Practical assistance & 3 & 0.8 & 0.76 & 0.86 & $<0.001$ \\
Support from friends and other young people & 8 & 0.92 & 0.73 & 0.84 & $<0.001$ \\
Dealing with feelings & 8 & 0.92 & 0.78 & 0.87 & $<0.001$ \\
Understanding from my family & 5 & 0.88 & 0.88 & 0.94 & $<0.001$ \\
My relationship with my siblings with cancer & 7 & 0.91 & 0.9 & 0.94 & $<0.001$ \\
Total & 45 & 0.97 & 0.94 & 0.97 & $<0.001$ \\
\hline
\end{tabular}


a qualitative study for identifying psychosocial support of sisters/brothers of someone with cancer, John.s considers spending leisure time, visiting places far from the cancer experience, having some fun and spending time with friends as their main needs. It is also consistent with the domain of Time Out and Recreation of the instrument in the current study (John, 2002).

The domain of Practical assistance includes the need to gain support regarding everyday life problems and practical issues such as housework, transportation, focusing on school assignments, extracurricular classes, university, work, and generally all the changes that may happen following the sick child's treatment and recovery at home (Patterson et al., 2011). It is consistent with the class of need for Instrumental support (meaning immediate help or financial assistance to make siblings able to do their duties properly or take care of themselves) in the study of John (2002).

Nolbris and Hellström (2005) also regard the need for support, either at the onset of the disease or after the death of the sick child, with Loneliness, Places of refuge. It is conceptually and semantically close to that of the domain of Practical assistance in the current study which is associated with the feeling of being forgotten by family and close relatives and the lack of support is semantic. It explains these needs in adolescents and presents this domain of the instrument.

The domain of Support from the part of my friends and other young people reflects the need to feel the support of a group of teenage friends, as well as other adolescents with similar experiences in having a sibling with cancer (Patterson et al., 2011). Olivier d'Avignon et al., (2017) regarded the need for peer support as the domains of School life and Relationship with peers in Needs Inventory for Siblings of Critically Ill Children (IBesFEMS/ 1'Inventaire des Besoins de la Fratrie d'Enfants Malades Se've'rement). These express the adolescents' need to be understood by school authorities or peers, so that they can live a normal life despite their situation. Nolbris and Hellström, (2005) also referred to the support from the part of friends and relatives as one of adolescents' needs, which was in line with this domain of the current study. Considering that adolescents would like to be at the center of attention and have their friends' approval of them, there are several evidences reflecting the need for support from the part of friends, which justifies the necessity of this domain's being present in the current instrument (Hockenberry and Wilson, 2015).

The domain of Dealing with feelings focuses on the adolescents' need to express their feelings about having a sibling with cancer, its impact on their lives, and also the need for help in order to handle the feelings like grief, sorrow, anxiety and anger (Patterson et al., 2011). According to Nolbris and Hellström, (2005) the adolescents had reactions such as sadness, the fear of losing the sick sibling, emotional adjustment problems and recalling memories after their sibling's death, which was consistent with the instrument discussed in this study. Furthermore, Woodgate (2006) also proposed Enduring sadness in the adolescent siblings of the children diagnosed with cancer. Considering the adolescents' behavioral responses during a crisis in the form of sorrow and grief caused by the disease, severe medical conditions and family issues, it is possible to confirm this domain's being included in the current research instrument (Hockenberry and Wilson, 2015).

The Domain of Understanding from my family reflects the adolescents' need to receive support and assistance from family, to participate in discussions and decision-makings, and generally the need for being a part of their sibling's illness, as well as providing help to the family if needed (Patterson et al., 2011). In this domain, the item of "To feel that I am just as important and valued as my sibling with cancer" with high eigenvalue, is in line with the concept of Being present in Woodgate (2006)'s study, i.e. being present in the family and participating in care provision for the sick person.

Olivier D'Avignon et al., (2017) showed that the domains of Relation with significant adults, Family life and Relation with parents were consistent with Understanding from the part of my family in the present study. Since they are at the phase of emotional sensitivity, adolescents have not learned to properly deal with their emotions and adapt to the tough situation yet, and need assistance and cooperation in this regard. This justifies the necessity of parents being beside their adolescents in difficult conditions, and confirms this domain of the instrument too (Hockenberry and Wilson, 2015).

The domain of my relation with my sibling with cancer explores the need for help regarding the sibling's relation with his/her sick sibling and the related challenges following cancer diagnosis (Patterson et al., 2011). This is compatible with the domain of Relation with the sick child in Needs Inventory for Siblings of Critically Ill Children (IBesFEMS) and also the domain of Committing to keeping my family together in Woodgate (2006) 's study, for protecting parents and the sick child against the causes of additional pain and stress (Olivier d'avignon et al., 2017).

Briefly, it can be said that similar studies confirm the framework of this instrument and its seven-factor structure. Additionally, the reliability of the whole instrument is appropriate too. The calculated Cronbach's alpha implies the high internal consistency of the instrument and each of its domains, which is also consistent with the outcomes of the original instrument.

In the current study, high reliability was reported for the domains of Support from the part of my friends and other young people, Dealing with feelings, My relationship with my sibling with cancer, which was in line with the original version.

The test-retest reliability of the instrument was also evaluated as appropriate, since the co-efficient between 0.75 and 1 shows excellent reliability. The findings of this study approved the applicability of the Persian version of the Sibling Cancer Needs Instrument (SCNI) in measuring the adolescents' needs in the Iran. It seems that the current study can be a prelude to further researches in this field in Iran.

In conclusion, following cancer diagnosis in one of the family members and its impact on family and as a result community health, the needs and health of family 
members, especially those of the healthy children, have to be taken into account too, in addition to the patient's health issues. In the meantime, adolescents need more attention and support due to their special condition during puberty, and meeting their physical, emotional, psychological and social needs plays a significant role in their individual and social life. Therefore, the presence of a valid and reliable instrument for assessing these needs is of great importance. While the psychometrically evaluated instrument in the present study has high validity and reliability, doing further research will eliminate its possible deficiencies and facilitates its use.

\section{Acknowledgements}

The current study is part of the research project approved by the research council of Shahid Beheshti University of Medical Sciences and also a part of the master's thesis. The researcher expresses her gratitude to all those who have contributed to the research, especially all the managers, staff and adolescents who participated in the research in the selected hospitals of medical universities of Tehran. Ethical code: IR.SBMU. PHNM.1395.742

\section{References}

Alderfer MA, Hodges JA (2010). Supporting siblings of children with cancer: A need for family-school partnerships. School Ment Health, 2, 72-81.

Arab M, Abbaszadeh A, Ranjbar H, Pourbaloli B, Ryany M (1391). The study of psychosocial problems in children with thalassemia and their brothers and sisters. IJNR, 7, 53-61.

Azarbarzin M, Taleghani F, Malekian A (2015). Adolescent made of crystal Psychological problems of adolescents who have a parent with cancer- a qualitative research. Med Sci $J, 25,223-9$.

Clinton-McHarg T, Carey M, Sanson-Fisher R, Shakeshaft A, Rainbird K (2010). Measuring the psychosocial health of adolescent and young adult (AYA) cancer survivors: a critical review. Health Qual Life Outcomes, 8, 25-38.

Dambi J, Makotore F, Kaseke F (2015). The impact of caregiving a child with cancer: A cross sectional study of experiences of zimbabwean caregivers. J Palliat Care Med, 5, 230.

Decker C, Phillips CR, Haase JE (2004). Information needs of adolescents with cancer. JOPON, 21, 327-34.

Grant S, Carlsen K, Bidstrup PE, et al (2012). Parental separation and pediatric cancer: A Danish cohort study. Pediatrics, 129, 1187-91.

Hockenberry MJ, Wilson D (2015). Wong's nursing care of infants and children, Mosby/Elsevier,St Louise Missouri.

John S M (2002). A Qualitative exploration of psychosocial support for siblings of children with cancer. J Pediatr Nurs, 17, 327-37.

McDonald F, Patterson P, White K, Butow P, Bell ML (2015). Predictors of unmet needs and psychological distress in adolescent and young adult siblings of people diagnosed with cancer. Psychooncology, 24, 333-40.

Nolbris M, Hellström AL (2005). Siblings' needs and issues when a brother or sister dies of cancer. JOPON, 22, 227-33.

Olivier d'avignon M, Dumont S, Valois P, Cohen SR (2017). The needs of siblings of children with a life-threatening illness, part 2: Psychometric validation of the IBesFEMS. Palliat Support Care, 15, 20-31.
Patterson P, McDonald FEJ, Butow P, et al (2014). Psychometric evaluation of the Sibling Cancer Needs Instrument (SCNI): an instrument to assess the psychosocial unmet needs of young people who are siblings of cancer patients. Support Care Cancer, 22, 653-65.

Patterson P, Millar B, Visser A (2011). The development of an instrument to assess the unmet needs of young people who have a sibling with cancer piloting the Sibling Cancer Needs Instrument (SCNI). JOPON, 28, 16-26.

Peek G, Melnyk BM (2010). Coping interventions for parents of children newly diagnosed with cancer: an evidence review with implications for clinical practice and future research. Pediatr Nurs, 36, 306-13.

Prchal A, Landolt MA (2012). How siblings of pediatric cancer patients experience the first time after diagnosis: a qualitative study. Cancer Nurs, 35, 133-40.

Rachele JN, Washington TL, Cuddihy TF, Barwais FA, McPhail SM (2013). Valid and reliable assessment of wellness among adolescents: Do you know what you're measuring?. IJW, 3, 162-72.

Sahib Alzamani M, Bashkali M, Abdollahi Mofrad Z (1389). Investigating the relationship between lifestyle and self-esteem among teenage girls in public high schools in Tehran. Med J of Islamic Azad Univ, 20, 45-51.

Silbermann M, Fink RM, Min S-J, et al (2015). Evaluating palliative care needs in Middle Eastern countries. $J$ Palliat Med, 18, 18-25.

Sooki Z, Sharifi K, Taghrebi Z, Akbari H, Mostaghizhna E (1389). Prevalence of depression and its correlation with the rate of satisfaction of psychosocial needs by parents in female high school students of Kashan in 1389. Feyz, 14, 256-63.

Torabi F, Sajjadi M, Nourian M, Borumandnia N, Shirinabadi Farahani A (2016). The effects of spiritual care on anxiety in adolescents with cancer. Support Care Cancer, In press.

Woodgate RL (2006). Siblings' experiences with childhood cancer. Cancer Nurs, 29, 406-14.

Yang HC, Mu PF, Sheng CC, Chen YW, Hung GY (2016). A systematic review of the experiences of siblings of children with cancer. Cancer Nurs, 39, 12-21.

Zebrack BJ, Corbett V, Embry L, et al (2014). Psychological distress and unsatisfied need for psychosocial support in adolescent and young adult cancer patients during the first year following diagnosis. Psychooncology, 23, 1267-75.

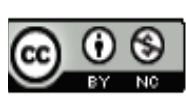

This work is licensed under a Creative Commons AttributionNon Commercial 4.0 International License. 